\title{
Fatores de risco associados à Síndrome de Burnout em servidores da Universidade Federal de Santa Maria
}

\author{
Risk factors associated with Burnout Syndrome in servers of the
} Federal University of Santa Maria

\author{
Steffani Nikoli Dapper', Sandra Leonara Obregon", \\ Luis Felipe Dias Lopes'", Roselaine Ruviaro Zanini'v
}

\begin{abstract}
RESUMO
A Síndrome de Burnout é considerada como um esgotamento físico e mental provocado por condições de trabalho desgastantes que levam o trabalhador ao adoecimento. Autores destacam que as variáveis ocupacionais dos indivíduos podem contribuir para o desenvolvimento da Síndrome. Neste sentido, o objetivo deste estudo foi analisar os fatores de risco associados ao desenvolvimento da Síndrome de Burnout em docentes e técnicos administrativos da Universidade Federal de Santa Maria. Para tanto, foi realizada uma pesquisa descritiva, quantitativa, de levantamento, do tipo survey, com 556 docentes e 955 técnicos administrativos. Para a realização do presente estudo foram aplicados dois instrumentos de pesquisa, o primeiro composto pelos dados sóciodemográficos e sócioprofissionais dos respondentes e, o segundo, pela escala de Síndrome de Burnout (MBI-GS) de Tamayo (2002). A análise dos dados foi realizada por meio de estatísticas descritivas e regressão logística. A partir dos resultados foi possível verificar, no modelo de regressão logística univariado, que ter idade entre 23 e 35 anos diminui em $49,80 \%$ a chance do docente e $43,00 \%$ do técnico administrativo apresentarem exaustão emocional, comparado com indivíduos maiores de 56 anos e que, em relação ao tempo de serviço, os docentes e TAEs que apresentaram tempo de 0 a 10 anos de instituição, possuem 42\% e 36\%, respectivamente, menos chance de ter exaustão emocional quando comparados com docentes e TAEs que apresentam 21 ou mais anos de serviço. A partir dos resultados foi possível verificar que os docentes e TAEs que estão trabalhando há menos tempo na instituição, possuem menos exaustão emocional, ou seja, apresentam, em menor nível, sensações como a falta energia, fadiga, sobrecarga e esgotamento moral, físico, emocional e psicológico.
\end{abstract}

Palavras-chave: Regressão logística. Síndrome de Burnout.Servidores

Iv Universidade Federal de Santa Maria. Brasil. e-mail: rrzanini63@gmail.com
} 


\begin{abstract}
Burnout Syndrome is considered as a physical and mental exhaustion due to working conditions that cause wear and tear to the worker. Highlighted authors that as occupational variables of individuals can contribute to the development of the Syndrome. In this sense, the objective of this study was to analyze the risk factors associated with the development of Burnout Syndrome in documents and administrative technicians at the Federal University of Santa Maria. For this, a descriptive, quantitative survey survey was carried out, with 556 documents and 955 administrative technicians. To carry out the present study, two research instruments were used, the first composed of respondents' socio-demographic data and health professionals, and the second, by the Tamayo (2002) Burnout Syndrome scale (MBI-GS). Data analysis was performed using descriptive statistics and logistic regression. From the results it was possible to verify, no univariate regression logon model, that age between 23 and 35 years decreased by $49.80 \%$ the chance of being documented and $43.00 \%$ of the administrative technician to present emotional exhaustion, comparing with larger participants of 56 years and, in relation to the length of service, documents and TAEs that have a period of 0 to 10 years of institution, have $42 \%$ and $36 \%$, respectively, less chance of emotional exhaustion when compared with documents and TAEs that perform 21 or more years of service. From the results, it was possible to verify the documents and TAEs that have been working for less time in the institution, that have less emotional exhaustion, that is, display, at lower levels, sensations such as lack of energy, fatigue, overload and moral, physical exhaustion, emotional and psychological.
\end{abstract}

Keywords: Logistic regression. Burnout syndrome. University 


\section{INTRODUÇÃO}

Diante dos impactos e transformações de ordem socioeconômica, demográfica, política e tecnológica, com o aumento das demandas e das exigências no trabalho para a garantia da qualidade e da produção dos serviços, o perfil do trabalho e dos trabalhadores modificou-se para adaptar-se às inovações tecnológicas e os novos modelos gerenciais de qualidade estabelecidos. Em decorrência disso, os trabalhadores foram sofrendo constantes tensões e pressões, o que acabou impactando na sua saúde física e emocional, levando-os a desenvolverem novos padrões de comportamento que influenciaram na estrutura e no funcionamento das organizações (ZANELLI, 2010).

Nessa perspectiva, os trabalhadores, tanto na natureza do trabalho, quanto no contexto em que exercem suas funções, estão expostos a diversos estressores ocupacionais que os tornam vulneráveis ao desgaste físico e emocional. Esses estressores são decorrentes do excesso de demandas, responsabilidades e más condições de trabalho. As condições de sofrimento emocional, relacionadas ao trabalho, podem ser definidas como Síndrome de Burnout (SB) ou Síndrome do Esgotamento Profissional, a qual consiste em um tipo de estresse resultante da constante e repetitiva pressão emocional, aliada ao intenso envolvimento com pessoas por períodos prolongados (LIMONGI-FRANÇA; RODRIGUES, 2012).

A SB é considerada um dos agravos ocupacionais de maior impacto físico, emocional e social para os indivíduos e surge como uma resposta crônica aos estressores presentes no contexto do trabalho. Além disso, afeta a saúde física e emocional do trabalhador, de modo a interferir nos relacionamentos interpessoais, despersonalização, sentimentos negativos de baixa eficácia pessoal, transtornos ansiosos ou depressivos, abuso de álcool e substâncias, queda na produtividade, baixo envolvimento no trabalho, carga de trabalho e absenteísmo (PERERRÉ; ROSSI; SAUTER, 2007).

Nesse contexto, Maslach, Schaufeli e Leiter (2001) definiram Burnout como uma resposta prolongada a estressores crônicos a nível pessoal e relacional no trabalho, determinado a partir das dimensões conhecidas como: exaustão emocional, 
despersonalização e reduzida realização profissional. A SB é considerada um fenômeno multidimensional e complexo, resultante da interação de aspectos individuais e organizacionais, e seu desenvolvimento também pode estar relacionado ao tipo de trabalho realizado. A exaustão emocional se refere à sensação de não poder dar mais de si a nível emocional e pessoal. A despersonalização compreende a nível social, a atitude distante perante o trabalho e as pessoas em geral e, a nível profissional, a falta de realização profissional se refere à sensação de não realizar adequadamente as tarefas e de se considerar incompetente.

Embora a SB afete várias profissões, os estudos relacionados a este tema centram-se especialmente na área do ensino e serviços de saúde, por se tratarem de atividades que envolvem intenso contato com pessoas (MASLACH; LEITER, 1999). Nesse sentido, considerando estes fenômenos e a relevância de seus impactos nas organizações, destaca-se a necessidade de estudar esses construtos no contexto das Instituições de Ensino Superior (IES), vistas como desafiadoras e estressantes com repercussões evidentes na saúde e no desempenho dos profissionais, ameaçando o bem-estar e a autoestima, podendo levar ao desenvolvimento de sentimentos negativos, como a desmotivação e a insatisfação (REIS et al., 2006).

Carlotto e Câmara (2008) evidenciaram em seu estudo que a SB tem mostrado maior impacto na vida dos profissionais da área da educação do que em outras, influenciando na qualidade de vida e na saúde desses profissionais. Em decorrência desse novo cenário, os servidores de uma instituição pública de ensino podem estar com níveis de estresse elevados, podendo estar sofrendo problemas individuais que podem comprometer o desenvolvimento do seu trabalho. Diante disso, definiu-se como problema de pesquisa a seguinte questão: Quais os fatores que influenciam o desenvolvimento da Síndrome de Burnout em servidores de uma instituição pública?. A partir da problemática exposta, o presente estudo teve como objetivo analisar os fatores de risco associados ao desenvolvimento da Síndrome de Burnout em docentes e técnicos administrativos da Universidade Federal de Santa Maria (UFSM). 


\section{SÍNDROME DE BURNOUT}

A origem do termo estresse surgiu na área da Engenharia, no início do século XIX, com o significado de tensão ou pressão. A partir deste significado, foram realizados testes que investigaram o quanto um material seria capaz de suportar uma força aplicada a ele antes de ser rompido (BAUK, 1985).

O estresse foi definido pelo endocrinologista Hans Selye como uma reação inespecífica do organismo a qualquer estímulo, elaboradas pelo sistema biológico como resposta a situações nocivas ao organismo. Assim, as alterações apresentadas pelo organismo, em decorrência de um estressor, significavam uma reação do corpo na tentativa de manter a homeostase. Deste modo, o autor explicou essas reações como a Síndrome da Adaptação Geral (SAG), que ocorre em três fases: alarme, resistência e exaustão (SELYE, 1959). A fase de alarme origina-se na resposta inicial a um estressor, na qual ocorre alteração da homeostasia, preparando o organismo para a luta ou fuga. Na permanência do estressor, ocorre a fase da resistência, na tentativa de recuperar a homeostasia. Na fase de exaustão, ocorrem sinais semelhantes aos da reação de alarme, mas que podem se intensificar, levando ao surgimento de doenças (LIPP, 1996).

A Síndrome de Burnout é um tipo de estresse ocupacional que acomete profissionais envolvidos com qualquer tipo de cuidado em uma relação de atenção direta, contínua e altamente emocional (MASLACH; LEITER, 1999). O termo Burnout é de origem inglesa, "burn" significa queimar e "out" é algo fora ou exteriorizado em que no contexto significa "morrer de tanto trabalhar" (ALMEIDA; SOUZA; CARLOTTO, 2009). O processo evolutivo do Burnout é progressivo, podendo levar anos para que se manifeste, geralmente, não sendo percebido pelo indivíduo (FRANÇA, 1987). A Síndrome de Burnout teve sua introdução no meio científico a partir dos estudos do psicanalista Herbert J. Freudenberger, no ano de 1974, em uma revista de psicologia, na qual foram descritas observações de jovens voluntários com quem trabalhava em uma determinada clínica gratuita de dependentes químicos, localizada na cidade de Nova York, nos Estados Unidos. Durante o estudo foram observados as tensões e ansiedades desses indivíduos (INNSTRAND et al., 2011). 
A propagação do tema deve-se à Freudenberger e, posteriormente, à psicóloga social Christina Maslach, que ampliou seus estudos com profissionais da saúde e serviços sociais, constatando que profissionais com a Síndrome de Burnout apresentavam comportamentos de distanciamento pessoal e atitudes negativas (TAMAYO, 2008). A SB tem ganhado notoriedade e reconhecimento em vários países, assim como de pesquisadores e profissionais identificada como uma problemática social e organizacional que necessita de investimento, atenção e melhoria com foco na sua prevenção e diminuição, sendo vista como um dos desafios do século XXI para a saúde ocupacional (RAWOLLE et al., 2016). Diante disso, a Síndrome de Burnout vem sendo estudada devido aos custos elevados para as organizações, decorrentes dos problemas como a rotatividade de pessoal, produtividade e qualidade, estando associada a diferentes tipos de disfunções pessoais, de ordem física e emocional, que podem levar a perda da capacidade laboral do indivíduo (FARBER, 1991).

No cenário brasileiro, a primeira publicação sobre Burnout foi realizada no ano de 1987, pelo médico cardiologista Hudson Hubner França. Na década de 90 foram realizadas novas produções. No ano de 1999 a SB foi incluída no Decreto nº 3.048 em 6 maio, no Anexo II da Regulamentação da Previdência Social, fazendo referência aos Agentes Patogênicos causadores de Doenças Profissionais (GARCIA, 2014). O artigo 20 da Lei 8.213/91 ampliou o rol de doenças ocupacionais sendo reconhecido pela legislação brasileira que os esforços no trabalho podem resultar no desequilíbrio mental (FONSECA, 2013). Sendo assim, em regra, para ser considerada uma doença profissional ou do trabalho, ela deve subsumir o conceito de transtornos mentais e de comportamentos relacionados ao trabalho (grupo V da CID-10), no qual o inciso XII refere-se à Síndrome de Burnout como uma sensação de "estrar acabado" (BENEVIDESPEREIRA, 2010). Muitas investigações tem sido produzidas com o intuito de identificar as variáveis que podem provocar a Síndrome de Burnout. Nesse sentido, BenevidesPereira (2010) realizou um estudo pressupondo que as características organizacionais, do trabalho e sociais poderiam ser fatores facilitadores e/ou desencadeadores da SB, conforme exibido no resumo esquemático abaixo. 
Figura 1 - Facilitadores e/ou desencadeadores da Síndrome de Burnout

\begin{tabular}{|c|c|}
\hline \multicolumn{2}{|c|}{ Facilitadores e/ou Desencadeadores do Burnout } \\
\hline $\begin{array}{l}\text { Características Pessoais } \\
\text { Idade } \\
\text { Sexo } \\
\text { Nivel educacional } \\
\text { Filhos } \\
\text { Personalidade } \\
\text { - Hardness, a personalidade resistente ao } \\
\quad \text { estresse } \\
\text { - Locus de Controle } \\
\text { - Padrão de personalidade Tipo A } \\
\text { - Variáveis do 'self' } \\
\text { - } \quad \text { Neuroticicismo } \\
\text { - Tipo Emocional } \\
\text { - Otimismo x Pessimismo } \\
\text { - Perfeccionismo } \\
\text { Sentido de Coerência } \\
\text { Motivação, Idealismo } \\
\text { Características Organizacionais } \\
\text { Ambiente Físico } \\
\text { Mudanças Organizacionais } \\
\text { Normas Institucionais } \\
\text { Clima, Burocracia, Comunicação } \\
\text { Autonomia, Recompensas e Segurança }\end{array}$ & $\begin{array}{l}\text { Características do Trabalho } \\
\text { Tipo de Ocupação } \\
\text { Tempo de Profissão } \\
\text { Tempo na Instituição } \\
\text { Trabalhos por Turnos } \\
\text { Sobrecarga } \\
\text { Relacionamento entre colegas de } \\
\text { trabalho } \\
\text { Relação Profissional-Cliente } \\
\text { Tipo de Cliente } \\
\text { Conflito de Papel } \\
\text { Ambiguidade de papel } \\
\text { Suporte Organizacional } \\
\text { Satisfação, Controle } \\
\text { Responsabilidade } \\
\text { Pressão } \\
\text { Possibilidade de progresso } \\
\text { Percepção de Inequidade } \\
\text { Conflito com os Valores Pessoais } \\
\text { Falta de Feedeback } \\
\text { Características Sociais } \\
\text { Suporte social } \\
\text { Suporte familiar } \\
\text { Cultura } \\
\text { Prestigio }\end{array}$ \\
\hline
\end{tabular}

Fonte: Benevides-Pereira (2010)

Em relação ao gênero, Maslach, Schaufeli e Leiter (2001) mencionam que esta variável não é um antecedente consistente da SB, pois os níveis em cada uma das três dimensões, apresentam-se diferentes para homens e mulheres. Na pesquisa de Bakker, Demerouti e Schaufeli (2002) realizada com 2.919 respondentes, identificou-se que o gênero feminino apresenta maiores níveis na dimensão Exaustão Emocional não obtendo conclusões a respeito da dimensão Despersonalização.

Contudo, de acordo com a pesquisa de Pinto (2000) e Maslach, Schaufeli e Leiter (2001) salientam que profissionais do gênero masculino constantemente apresentam níveis mais elevados na dimensão Despersonalização, enquanto Maslach, Schaufeli e Leiter (2001) e Bakker, Demerouti e Schaufeli (2002) denotam que os profissionais do gênero feminino têm índices superiores na dimensão Exaustão Emocional (BENEVIDESPEREIRA, 2002). No que tange ao nível educacional, estudos apontam que quanto maior o nível educacional maiores os níveis da SB na dimensão Exaustão Emocional (BENEVIDES-PEREIRA, 2002; MASLACH; JACKSON,1981). Nesse contexto, Maslach (1976) afirma que a SB pode receber diferentes nomes para o mesmo fenômeno, podendo surgir em várias profissões e em diversos ambientes organizacionais, porém, dentre as profissões mais vulneráveis, estão as que envolvem serviços, tratamento ou educação 
(MASLACH; LEITER, 1999). Diante disso, a definição mais aceita do Burnout é a fundamentada na perspectiva de Maslach, sendo esta configurada em três dimensões: exaustão emocional, despersonalização e baixa realização pessoal no trabalho (MASLACH; JACKSON, 1981). Na concepção de Maslach (2007), a Exaustão Emocional (EE) está relacionada a aspectos individuais e, assim, o estresse individual configura-se como componente básico para a compreensão do Burnout. Essa dimensão refere-se à sensação de que os problemas que causam o estresse extrapolam a capacidade do indivíduo e estão esgotando seus recursos emocionais e físicos. Caracteriza-se por uma falta ou carência de energia, entusiasmo e um sentimento de esgotamento de recursos. Os principais antecedentes dessa dimensão são a sobrecarga de trabalho e o conflito intrapessoal.

A dimensão Despersonalização (DP) se refere ao contexto interpessoal do Burnout e à reação negativa, indiferente e distanciada em que os trabalhadores estabelecem com os diversos aspectos do trabalho. Esta dimensão desenvolve-se como proteção à exaustão emocional e pode levar, ao longo do tempo, a diminuição na produtividade do trabalho desempenhado e desenvolver reações negativas às pessoas no contexto do trabalho (MASLACH, 2007). Maslach e Jackson (1981) acreditam que nesta dimensão o profissional começa a tratar seus colegas, clientes e, a própria organização, como objetos, podendo desenvolver insensibilidade emocional.

O componente de autoavaliação do Burnout é representado pela dimensão da Baixa Realização Pessoal (RP) ou ineficácia, que se refere à sensação de incompetência e à falta de realização e produtividade no trabalho, como combinação das duas dimensões acima referidas (EE e DP). Essa sensação é diminuída pela autoeficácia e exacerbada pela falta de recursos no trabalho, de apoio social e de oportunidades para o desenvolvimento profissional, contribuindo para um sentimento de incompetência, ineficácia e baixa realização profissional (MASLACH, 2007). Maslach, Schaufeli e Leiter (2001) pontuam que, nas várias definições do Burnout, embora com algumas questões divergentes, todas encontram no mínimo cinco elementos comuns: 1) existe a predominância de sintomas relacionados à exaustão mental e emocional, fadiga e depressão; 2) a ênfase nos sintomas comportamentais e mentais e não nos sintomas 
físicos; 3) os sintomas do Burnout são relacionados ao trabalho; 4) os sintomas manifestam-se em pessoas "normais" que não sofriam de distúrbios psicopatológicos antes do surgimento da síndrome; 5) a diminuição da efetividade e desempenho no trabalho ocorre por causa de atitudes e comportamentos negativos.

\section{MATERIAIS E MÉTODOS}

No que tange à natureza da pesquisa, esta classifica-se como descritiva e, quanto à abordagem, como quantitativa. Em relação ao método de pesquisa, este é de levantamento do tipo survey, o qual tem como característica descobrir determinados atributos em relação a uma população, envolvendo a coleta e a quantificação de dados (BAKER, 2005).

\subsection{População e amostra do estudo}

A população do presente estudo foi composta por servidores da UFSM. A coleta dos dados ocorreu no ano de 2016, em que a população de servidores era de 4.708, os quais são subdivididos em duas categorias: docentes e técnicos administrativos em educação. Na Figura 2 pode ser observada a população do estudo.

Figura 1 - Total de servidores da UFSM ativos por categoria em 11 de abril de 2016.

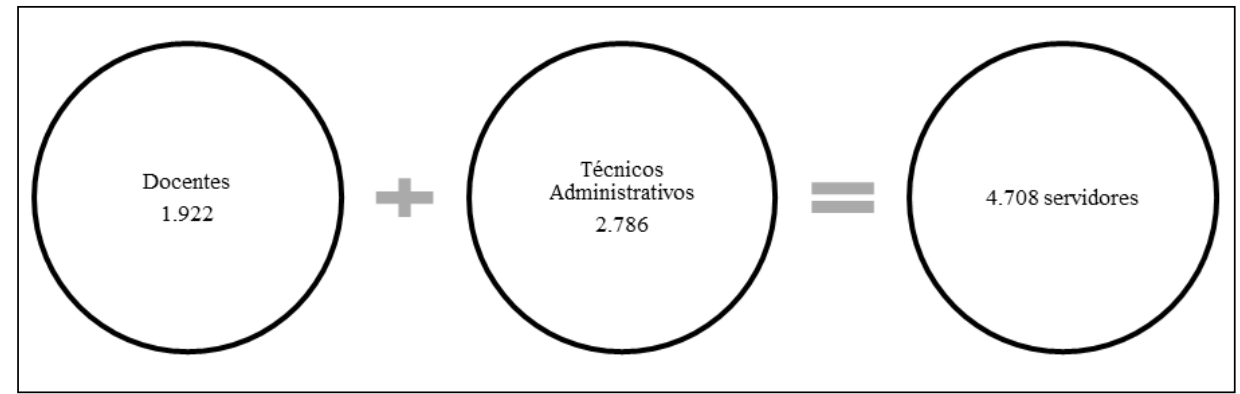

O instrumento de pesquisa foi enviado para os 4.708 servidores, sendo os mesmos convidados a participar da pesquisa via e-mail, o qual foi encaminhado pelo Centro de Processamento de Dados (CPD) da UFSM. No e-mail continham o Termo de Confidencialidade (TC), o Termo de Consentimento Livre e Esclarecido (TCLE) e os instrumentos de coleta de dados. Ao total, participaram da pesquisa, 1511 servidores, sendo 556 docentes e 955 técnicos administrativos em educação. Como critério de 
inclusão, adotou-se o fato do respondente ser docente ou técnico administrativo da UFSM e, como critério de exclusão, estar aposentado.

\subsection{Coleta de dados e instrumento de pesquisa}

Este estudo foi realizado a partir da aplicação do Protocolo de Pesquisa constituído em duas partes: Parte I - Dados sócio demográficos e sócio profissionais e Parte II - Escala de Síndrome de Burnout (MBI-GS). A coleta de dados foi realizada no período de 09 de agosto a 31 de outubro de 2016.

A fim de avaliar o nível da Síndrome de Burnout dos docentes e técnicos administrativos da UFSM, foi aplicada a escala Maslach Burnout Inventory - General Survey (MBI-GS) de Maslach e Jackson (1981), adaptada e validada para a língua portuguesa por Tamayo (2002), sendo que esta pode ser utilizada em populações que possuem diversos tipos de ocupações (MASLACH; SCHAUFELI; LEITER, 2001). A escala é composta por 16 variáveis que avaliam três dimensões: Exaustão Emocional (EE), Despersonalização (DP) e Envolvimento Pessoal no Trabalho (EPT). Os itens são medidos a partir de uma escala de seis pontos variando de 0 (nunca) a 6 (todo dia), conforme a frequência do sentimento.

\subsection{Tratamento e análise dos dados}

Após a coleta dos dados, estes foram organizados em uma planilha do software Excel, os quais, posteriormente, foram analisados utilizando o PASW, versão 18.0. Primeiramente, com o intuito de verificar a confiabilidade do instrumento, calculou-se o Alfa de Cronbach que, segundo Hair Jr. et al. (2009), é um coeficiente que avalia o grau de consistência inteira da escala. Os autores destacam que valores entre $0,7 \leq a<0,8$ representam índices aceitáveis, índices entre $0,8 \leq a<0,9$ são considerados um bom índice e $a>0,9$ diz respeito a índices ótimos, sendo que $a<0,6$ indicam que a escala não é confiável.

A análise do perfil sócio demográfico e sócio profissional dos docentes e técnicos administrativos foi realizada por meio de frequências relativas e absolutas, média e desvio-padrão. Para a análise do nível da Síndrome de Burnout nos servidores utilizouse da padronização das escalas. Essa padronização transforma os dados dispostos em 
escala ordinal, em escala de razão de 0 a 100\%, os quais são convencionados nas três categorias (Baixa, Média e Alta - Síndrome de Burnout). Logo, a padronização ocorreu da seguinte forma: Alta, para média de 66,68\% a 100\%, Média, para média entre 33,34\% e 66,67\% e Baixa para média de 0 a 33,33\%, de acordo com a seguinte equação (LOPES, 2016, p. 18):

$$
\mathrm{Sp}_{\mathrm{i}}=100 *\left(\frac{\text { SOMA }- \text { MÍNIMO }}{\text { MÁXIMO }- \text { MÍNIMO }}\right), \mathrm{i}=1,2,3, \ldots
$$

onde:

i = número de dimensões ou aspectos;

Soma = Somatório das respostas validas das dimensões ou aspectos;

Mínimo = menor soma possível das respostas válidas;

Máximo = maior soma possível das respostas válidas.

Para analisar os fatores de risco associados ao desenvolvimento da Síndrome de Burnout foi aplicada a regressão logística univariada e, posteriormente, a regressão logística múltipla. Zanini (2007) destaca que a regressão logística pode ser aplicada quando se tem uma variável dependente categórica dicotômica, ou seja, uma variável nominal ou não métrica. Esta deve possuir apenas dois grupos ou classificações como resultados possíveis, como, por exemplo, baixo ou alto, sim ou não, sucesso ou fracasso, etc.

Como variáveis dependentes foram consideradas as dimensões da Síndrome de Burnout (Exaustão Emocional, Despersonalização e Envolvimento Pessoal no Trabalho). Maslach, Jackson e Leiter (2018) destacam que não é possível juntar a pontuação das três dimensões para analisar se o indivíduo apresenta indícios do desenvolvimento da Síndrome de Burnout, pois as dimensões devem formar pontuações individuais e serem analisadas separadamente, pois possuem sentidos diferentes. Indivíduos que apresentam a média nas dimensões abaixo de três não são considerados com indício da presença das dimensões que compõe o Burnout, enquanto aqueles que apresentam médias iguais ou superiores a três são considerados indivíduos que podem apresentar, 
em determinado grau, a presença dos sintomas que caracterizam determinada dimensão (MASLACH; JACKSON; LEITER, 2018).

As variáveis dependentes utilizadas no estudo foram dicotômicas ou binárias, sendo classificadas em 0 e 1, em que 0 indica a ausência dos fatores de determinada dimensão e 1 a presença. As variáveis independentes utilizadas para a construção dos modelos de regressão logística dos docentes e TAEs, bem como as suas codificações, estão apresentadas, respectivamente, nos Quadros 1 e 2.

Quadro 1 - Variáveis utilizadas para a construção dos modelos de regressão logística dos docentes

\begin{tabular}{|c|c|c|}
\hline Variáveis & Denominação & Codificação \\
\hline \multirow{3}{*}{ Dependentes } & Exaustão Emocional (EE) & \multirow{3}{*}{$\begin{array}{l}\text { Ausência de Burnout-0 } \\
\text { Presença de Burnout-1 }\end{array}$} \\
\hline & Despersonalização (DP) & \\
\hline & Envolvimento pessoal no trabalho (EPT) & \\
\hline \multirow{21}{*}{ Independentes } & \multirow{2}{*}{ Sexo } & Feminino-0 \\
\hline & & Masculino-1 \\
\hline & \multirow{3}{*}{ Idade } & $\geq 56$ anos- 0 \\
\hline & & 36 a 55 anos- 1 \\
\hline & & 23 a 35 anos-2 \\
\hline & \multirow{3}{*}{ Escolaridade } & Doutorado-0 \\
\hline & & Mestrado-1 \\
\hline & & Graduação ou especialização-2 \\
\hline & \multirow{3}{*}{ Tempo de serviço } & $\geq 21$ anos- 0 \\
\hline & & 11 a 20 anos- 1 \\
\hline & & 0 a 10 anos-2 \\
\hline & \multirow{2}{*}{ Categoria do cargo } & Professor ensino superior- 0 \\
\hline & & Professor técnico-1 \\
\hline & \multirow{2}{*}{ Férias } & Não-0 \\
\hline & & Sim-1 \\
\hline & \multirow[b]{2}{*}{ Chefia } & Sim-0 \\
\hline & & Não-1 \\
\hline & \multirow{2}{*}{ Carga horária } & 20 e 40 horas -1 \\
\hline & & mais que 40 horas- 0 \\
\hline & \multirow{2}{*}{ Exerce o trabalho que gosta } & Não-0 \\
\hline & & Sim-1 \\
\hline
\end{tabular}


Quadro 2 - Variáveis utilizadas para a construção dos modelos de regressão logística dos técnicos administrativos

\begin{tabular}{|c|c|c|}
\hline Variáveis & Denominação & Codificação \\
\hline \multirow{3}{*}{ Dependentes } & Exaustão Emocional(EE) & \multirow{3}{*}{$\begin{array}{l}\text { Ausência de Burnout-0 } \\
\text { Presença de Bunout-1 }\end{array}$} \\
\hline & Despersonalização(DP) & \\
\hline & Envolvimento pessoal no trabalho(EPT) & \\
\hline \multirow{27}{*}{ Independentes } & \multirow{2}{*}{ Sexo } & Feminino-0 \\
\hline & & Masculino-1 \\
\hline & \multirow{3}{*}{ Idade } & $>56$ anos-0 \\
\hline & & 36 a 55 anos- 1 \\
\hline & & 23 a 35 anos- 2 \\
\hline & \multirow{5}{*}{ Escolaridade } & Doutorado-0 \\
\hline & & Mestrado-1 \\
\hline & & Especialização-2 \\
\hline & & Graduação-3 \\
\hline & & Primeiro e segundo grau-4 \\
\hline & \multirow{3}{*}{ Tempo de serviço } & $>21$ anos-0 \\
\hline & & 11 a 20 anos-1 \\
\hline & & 0 a 10 anos-2 \\
\hline & \multirow{5}{*}{ Categoria do cargo } & Classe A-4 \\
\hline & & Classe B-3 \\
\hline & & Classe C-2 \\
\hline & & Classe D-1 \\
\hline & & Classe $\mathrm{E}-0$ \\
\hline & \multirow{2}{*}{ Férias } & Não-0 \\
\hline & & Sim-1 \\
\hline & \multirow{2}{*}{ Chefia } & Sim-0 \\
\hline & & Não-1 \\
\hline & \multirow{3}{*}{ Carga horária } & 40 e acima de 40 horas -0 \\
\hline & & 30 horas- 1 \\
\hline & & 20 horas- 2 \\
\hline & \multirow{2}{*}{ Exerce o trabalho que gosta } & Não-0 \\
\hline & & Sim-1 \\
\hline
\end{tabular}

Para cada uma das variáveis dependentes foi realizada a regressão logística univariada, sendo que as variáveis que apresentaram p-valor menor ou igual a 0,25 foram candidatas a entrar no modelo múltiplo. Em seguida, as variáveis que apresentaram p-valor>0,05, na análise conjunta, foram sendo excluídas, uma a uma, sendo eliminadas as variáveis com o maior $p$-valor.

\subsection{Aspectos éticos}

Para a concretização do presente estudo, o projeto foi registrado no Gabinete de Projetos (GAP) do Centro de Ciências Sociais e Humanas (CCSH) da Universidade 
Federal de Santa Maria (UFSM). Em seguida, registrado no Sistema Nacional de Ética em pesquisa (SISNEP) sob certificado de apresentação para apreciação ética (CAAE).

Posteriormente a aprovação do projeto, o mesmo foi protocolado no Comitê de Ética em Pesquisa (CEP) da UFSM, reconhecido pela Comissão de Ética em Pesquisa (CONEP), respeitando a resolução 196/96 do Conselho Nacional em Saúde (CNS) (BRASIL, 1996). Assim, com a aprovação do CEP, os pesquisadores iniciaram a coleta de dados. Deste modo, o Termo de Consentimento Livre e Esclarecido (TCLE) e o Protocolo de Pesquisa contém todos os preceitos éticos que estão estabelecidos pela resolução 196/96 do CNS, sendo este o responsável por regulamentar a ética em pesquisa com seres humanos e as demais normas complementares do CNS.

Os participantes do estudo poderão ter acesso aos dados coletados (TCLEs e Protocolo de Pesquisa), os quais ficarão disponíveis através do arquivamento no Núcleo de Pesquisa em Administração (NUPEAD) sob responsabilidade do pesquisador coordenador Prof. Dr. Luis Felipe Dias Lopes (Orientador do estudo), durante o período de cinco anos, de acordo com a Lei dos Direitos Autorais n. 9.610 (BRASIL, 1998). Além disso, o sigilo de identidade dos participantes é assegurado no momento da publicação dos resultados. Para fins de concretização deste estudo, o mesmo recebeu o registro CAAE sob $n^{\circ} 57883816.4 .0000 .5346$.

\section{RESULTADOS E DISCUSSÕES}

\subsection{Caracterização do perfil sociodemográfico e socioprofissional da amostra}

No Quadro 3 é apresentado o perfil sócio demográfico e sócio profissional dos servidores da amostra, no qual pode-se afirmar que a maioria dos respondentes é predominantemente constituído pelo sexo feminino (55,33\%), 33,62\% possuem idade entre 31 a 40 anos, sendo que 32,36\% possuem doutorado. A maioria dos respondentes (58,84\%) possuem até 10 anos de tempo de serviço, sendo que 63,20\% possuem o cargo de Técnico Administrativo em Educação, classificados como cargo de categoria Classe D (28,92\%) e 36,80\% são Docentes, nos quais 33,88\% são Docentes do Ensino Superior. Durante o período da coleta de dados, a maioria dos servidores pesquisados (80,87\%) não tiraram férias nos últimos 60 dias, 78,09\% não possuem 
função de chefia, 66,58\% trabalham 40 horas semanais e 92,72\% da amostra afirmaram gostar do trabalho que exercem na UFSM.

Quadro 3 - Caracterização geral do perfil sóciodemográfico e sócioprofissional dos servidores da amostra $(n=1.511)$

\begin{tabular}{|c|c|c|c|}
\hline Variáveis & Categorias & Frequência & Percentual \\
\hline \multirow{2}{*}{ Sexo } & Feminino & 836 & $55,33 \%$ \\
\hline & Masculino & 675 & $44,67 \%$ \\
\hline \multirow{4}{*}{ Faixa Etária } & Até 30 anos & 169 & $11,18 \%$ \\
\hline & 31 a 40 anos & 508 & $33,62 \%$ \\
\hline & 41 a 50 anos & 374 & $24,75 \%$ \\
\hline & 51 anos em diante & 460 & $30,44 \%$ \\
\hline \multirow{6}{*}{ Escolaridade } & Ensino Fundamental & 7 & $0,46 \%$ \\
\hline & Ensino Médio & 100 & $6,62 \%$ \\
\hline & Ensino Superior & 243 & $16,08 \%$ \\
\hline & Especialização & 372 & $24,62 \%$ \\
\hline & Mestrado & 300 & $19,85 \%$ \\
\hline & Doutorado & 489 & $32,36 \%$ \\
\hline \multirow{4}{*}{ Tempo de Serviço } & Até 10 anos & 889 & $58,84 \%$ \\
\hline & 11 a 20 anos & 249 & $16,48 \%$ \\
\hline & 21 a 30 anos & 253 & $16,74 \%$ \\
\hline & 31 anos em diante & 120 & $7,94 \%$ \\
\hline \multirow{2}{*}{ Cargo } & Docente & 556 & $36,80 \%$ \\
\hline & Técnico Administrativo em Educação & 955 & $63,20 \%$ \\
\hline \multirow{7}{*}{ Categoria do Cargo } & $\begin{array}{l}\text { Técnico Administrativo em Educação } \\
\text { - Classe A }\end{array}$ & 3 & $0,20 \%$ \\
\hline & $\begin{array}{l}\text { Técnico Administrativo em Educação } \\
\text { - Classe B }\end{array}$ & 15 & $0,99 \%$ \\
\hline & $\begin{array}{l}\text { Técnico Administrativo em Educação } \\
\text { - Classe C }\end{array}$ & 137 & $9,07 \%$ \\
\hline & $\begin{array}{l}\text { Técnico Administrativo em Educação } \\
\text { - Classe D } \\
\end{array}$ & 437 & $28,92 \%$ \\
\hline & $\begin{array}{l}\text { Técnico Administrativo em Educação } \\
\text { - Classe E }\end{array}$ & 363 & $24,02 \%$ \\
\hline & $\begin{array}{l}\text { Docente do Magistério do Ensino Básico, } \\
\text { técnico e Tecnológico }\end{array}$ & 44 & $2,91 \%$ \\
\hline & Docente do Ensino Superior & 512 & $33,88 \%$ \\
\hline \multirow{2}{*}{$\begin{array}{l}\text { Indicativo de Férias } \\
\text { nos últimos } 60 \text { dias }\end{array}$} & Sim & 289 & $19,13 \%$ \\
\hline & Não & 1222 & $80,87 \%$ \\
\hline \multirow{2}{*}{$\begin{array}{l}\text { Possui função } \\
\text { de chefia }\end{array}$} & Sim & 331 & $21,91 \%$ \\
\hline & Não & 1180 & $78,09 \%$ \\
\hline \multirow{4}{*}{$\begin{array}{l}\text { Carga horária } \\
\text { semanal }\end{array}$} & 20 horas & 29 & $1,92 \%$ \\
\hline & 30 horas & 287 & $18,99 \%$ \\
\hline & 40 horas & 1006 & $66,58 \%$ \\
\hline & Acima de 40 horas & 189 & $12,51 \%$ \\
\hline \multirow{2}{*}{$\begin{array}{l}\text { Exerce o trabalho } \\
\text { que gosta }\end{array}$} & Sim & 1401 & $92,72 \%$ \\
\hline & Não & 110 & $7,28 \%$ \\
\hline
\end{tabular}


Na Tabela 1 podem ser observados os valores de Alfa de Cronbach obtidos na escala de Síndrome de Burnout. Com base na Tabela 1, verifica-se que os Alfas obtidos são considerados índices aceitáveis e bons, pois variam entre $07>a<0,9$ e assemelham-se da versão original americana que apresenta Alfas de Cronbach que variam de 0,71 a 0,90 (MASLACH; JACKSON, 1981).

Tabela 1- Alfa de Cronbach da escala de Síndrome de Burnout

\begin{tabular}{|lll|}
\hline Dimensões da Síndrome de Burnout & Variáveis & $\begin{array}{l}\text { Alfa de } \\
\text { Cronbach }\end{array}$ \\
\hline Exaustão Emocional & $29,30,31,32,33$ e 34 & 0,880 \\
Despersonalização & $35,36,37$ e 38 & 0,796 \\
Envolvimento Pessoal no Trabalho & $39,40,41,42,43$ e 44 & 0,879 \\
\hline Total da escala de Síndrome de Burnout & & 0,717 \\
\hline
\end{tabular}

Com o intuito de identificar a possível incidência da Síndrome de Burnout e suas dimensões nos Servidores da UFSM, analisaram-se as médias e os desvios padrão de cada dimensão, bem como a frequência das respostas. Na Tabela 2 são demonstrados os dados obtidos na pesquisa. 
Tabela 2 - Média, desvio padrão e frequência dos indicadores e dimensões da escala MBI-GS para os servidores

\begin{tabular}{|c|c|c|c|c|c|c|c|c|c|}
\hline \multirow{2}{*}{ Dimensões } & \multicolumn{7}{|c|}{ Frequência } & \multirow{2}{*}{ Média } & \multirow{2}{*}{$\begin{array}{l}\text { Desvio } \\
\text { Padrão }\end{array}$} \\
\hline & 0 & 1 & 2 & 3 & 4 & 5 & 6 & & \\
\hline \multicolumn{8}{|c|}{ EXAUSTÃO EMOCIONAL } & 2,96 & 1,679 \\
\hline $\begin{array}{l}\text { 30- Sinto-me emocionalmente esgotado com } \\
\text { o meu trabalho }\end{array}$ & 209 & 340 & 150 & 384 & 121 & 269 & 38 & 2,96 & 1,530 \\
\hline $\begin{array}{l}\text { 31- Sinto-me esgotado no final de um dia de } \\
\text { trabalho }\end{array}$ & 128 & 339 & 163 & 345 & 124 & 336 & 76 & 3,13 & 1,624 \\
\hline \multicolumn{10}{|l|}{ 32- Sinto-me cansado quando me levanto pela } \\
\hline \multicolumn{9}{|l|}{ encarar outro dia de trabalho } & 1,638 \\
\hline $\begin{array}{l}\text { 33- Trabalhar todo dia é realmente motivo de } \\
\text { tensão para mim }\end{array}$ & 481 & 363 & 116 & 236 & 72 & 174 & 69 & 2,79 & 1,681 \\
\hline $\begin{array}{l}\text { 34- Sinto-me acabado por causa do meu } \\
\text { trabalho }\end{array}$ & 566 & 372 & 123 & 209 & 72 & 129 & 40 & 2,56 & 1,585 \\
\hline $\begin{array}{l}\text { 35- Só desejo fazer meu trabalho e não ser } \\
\text { incomodado }\end{array}$ & 332 & 348 & 125 & 223 & 67 & 185 & 231 & 3,26 & 1,915 \\
\hline \multicolumn{8}{|c|}{ DESPERSONALIZAÇÃO } & 2,25 & 1,549 \\
\hline $\begin{array}{l}\text { 36- Sou menos interessado no meu trabalho } \\
\text { desde que assumi essa função }\end{array}$ & 963 & 239 & 78 & 108 & 33 & 56 & 34 & 2,44 & 1,611 \\
\hline $\begin{array}{l}\text { 37- Sou menos entusiasmado com o meu } \\
\text { trabalho }\end{array}$ & 684 & 425 & 103 & 140 & 39 & 77 & 43 & 2,24 & 1,577 \\
\hline $\begin{array}{l}\text { 38- Sou mais descrente sobre a } \\
\text { contribuição de meu trabalho para algo }\end{array}$ & 770 & 381 & 97 & 139 & 39 & 54 & 31 & 2,16 & 1,487 \\
\hline 39- Duvido da importância do meu trabalho & 1025 & 250 & 64 & 88 & 24 & 40 & 20 & 2,18 & 1,504 \\
\hline \multicolumn{8}{|c|}{ ENVOLVIMENTO PESSOAL NO TRABALHO } & 5,01 & 1,231 \\
\hline $\begin{array}{l}\text { 40- Sinto-me entusiasmado quando realizo } \\
\text { algo no meu trabalho }\end{array}$ & 28 & 35 & 39 & 171 & 112 & 505 & 621 & 4,94 & 1,251 \\
\hline $\begin{array}{l}\text { 41- Realizo muitas coisas valiosas no } \\
\text { meu trabalho }\end{array}$ & 18 & 58 & 68 & 178 & 105 & 530 & 554 & 4,77 & 1,377 \\
\hline $\begin{array}{l}\text { 42- Posso efetivamente solucionar os } \\
\text { problemas que surgem no meu trabalho } \\
\text { 43- Sinto que estou dando uma }\end{array}$ & 13 & 49 & 30 & 152 & 88 & 650 & 529 & 4,90 & 1,229 \\
\hline $\begin{array}{l}\text { contribuição efetiva para essa } \\
\text { organização }\end{array}$ & 17 & 51 & 37 & 115 & 88 & 433 & 770 & 5,09 & 1,282 \\
\hline 44- Na minha opinião, sou bom no que faço & 7 & 19 & 15 & 86 & 84 & 568 & 732 & 5,24 & 1,004 \\
\hline $\begin{array}{l}\text { 45- No meu trabalho, me sinto confiante de } \\
\text { que sou eficiente e capaz de fazer com que as } \\
\text { coisas aconteçam. }\end{array}$ & 14 & 34 & 22 & 119 & 80 & 541 & 701 & 5,12 & 1,149 \\
\hline
\end{tabular}

Com base na Tabela 2, ao analisar o índice médio da dimensão Exaustão Emocional, que é a primeira etapa do desenvolvimento da Síndrome de Burnout, verificou-se média de 2,96 indicando que a ocorrência de sentimentos como a falta de 
energia, o esgotamento físico e mental e a perda de entusiasmo, no qual o servidor chega ao seu limite, ocorre pelo menos uma vez ao mês ou algumas vezes durante o mês (CARLOTTO; PALAZZO, 2006; MASLACH, 2007). O questionamento "Só desejo fazer meu trabalho e não ser incomodado" obteve a maior média desta dimensão, demonstrando que os servidores sentem-se assim algumas vezes durante o mês. É importante ressaltar que mesmo que o índice médio da dimensão é considerado baixo, deve-se preocupar para que o mesmo não aumente, pois este influencia no aumento das demais dimensões, podendo prejudicar não só o indivíduo, como aqueles a sua volta.

No que tange à Despersonalização, esta obteve média de 2,25, indicando que a ocorrência de sentimentos de indiferença em relação ao trabalho e comportamentos de insensibilidade de modo que o servidor começa a tratar os demais de maneira fria, cínica e desumana, apresentando alterações na personalidade, ocorre uma vez ao mês ou menos (MASLACH; SCHAUFELI; LEITER, 2001; CHAN, 2006; CARLOTTO; PALAZZO, 2006). Quanto ao questionamento que obteve a maior média da dimensão "Sou menos interessado no meu trabalho desde que assumi essa função", este indica que os servidores, pelo menos uma vez ao mês ou algumas vezes durante o mês, sentem-se menos interessados no trabalho desde que assumiram a atual função. Ressalta-se que mesmo a dimensão Despersonalização ter atingido baixos índices da Síndrome de Burnout, torna-se necessário a Instituição atentar-se mais aos sintomas de seus Servidores e agir de maneira preventiva, já que muitas vezes estes apresentam-se de maneira imperceptível, influenciando no relacionamento entre os mesmos, com os discentes e a comunidade, podendo afetar diretamente na qualidade do ensino e na formação dos alunos. A Exaustão Emocional e a Despersonalização são consideradas por Schaufeli e Buunk (2003) como as dimensões que apresentam os principais sintomas da Síndrome de Burnout e ambos correspondem ao componente energético interpessoal, sendo consideradas o polo negativo da Síndrome. Em contrapartida, o Envolvimento Pessoal no Trabalho é o polo positivo, pois o profissional apresenta envolvimento com seu trabalho, tendo maior interesse pelas suas atividades e pelo desenvolvimento de sua competência pessoal e profissional (MASLACH; LEITER, 1999) 
Neste estudo, a dimensão Envolvimento Pessoal no Trabalho obteve média de 5,01 , indicando que os servidores sentem-se envolvidos com o trabalho algumas vezes durante a semana. Este índice é considerado alto para essa dimensão, indicando que os mesmos sentem satisfação, prazer e bem-estar ao desempenhar suas atividades diárias, pois sob a ótica de Montero-Marin et al. (2011), o baixo índice nesta dimensão confirma que os trabalhadores sentem-se insatisfeitos, infelizes, inadequados e fracassados em relação ao trabalho. No que tange ao questionamento "Na minha opinião, sou bom no que faço", este obteve a maior média desta dimensão, informando que os servidores sentem-se deste modo algumas vezes durante a semana, muito perto de sentirem-se assim todos os dias. O alto índice na dimensão Envolvimento Pessoal no Trabalho indica que os servidores sentem-se satisfeitos e reconhecidos com o seu desempenho profissional, indo ao encontro dos achados de Casini, Hubert e Kaelen (2016), ao constatarem que o reconhecimento profissional é um fator que previne e protege contra a Síndrome de Burnout e o desengajamento.

De acordo com Schaufeli et al. (2002), pode se afirmar que a maioria dos servidores pesquisados não apresenta a Síndrome de Burnout, pois as baixas médias nas dimensões Exaustão Emocional e Despersonalização e alta média para a dimensão Envolvimento Pessoal no Trabalho, não indicam a presença da mesma. Esse resultado vai ao encontro de outros estudos realizados em diferentes amostras de populações, como: trabalhadores de indústrias (GORSKI, 2015), policiais rodoviários federais (FREITAS et al., 2015) e médicos oftalmologistas (NAIR et al., 2017), os quais também não constataram a presença do Burnout na maioria da amostra.

\subsection{Indicadores da síndrome de Burnout nos servidores da UFSM}

Com o intuito de responder aos objetivos específicos deste estudo, realizou-se a padronização da escala MBI-GS. Deste modo, a padronização da escala MBI-GS pode ser vista na Tabela 3. 


\begin{tabular}{lccc} 
Tabela 3 - Padronização das dimensões da escala MBI-GS \\
\hline Dimensões da Síndrome de Burnout & Classificação & Frequência & Percentual \\
\hline \multirow{3}{*}{ Exaustão Emocional } & Alto & 220 & $15,02 \%$ \\
& Médio & 533 & $36,38 \%$ \\
& Baixo & 712 & $48,60 \%$ \\
Despersonalização & Alto & 23 & $2,32 \%$ \\
& Médio & 172 & $17,32 \%$ \\
& Baixo & 798 & $80,36 \%$ \\
Envolvimento Pessoal no Trabalho & Alto & 1255 & $83,33 \%$ \\
& Médio & 223 & $14,81 \%$ \\
& Baixo & 28 & $1,86 \%$ \\
\hline
\end{tabular}

Pode-se perceber que dos 1.511 servidores da UFSM participantes deste estudo, a maioria, 48,60\%, apresenta nível baixo de Exaustão Emocional. Esse resultado indica que grande parte dos servidores não sofrem com a falta de energia, frustação ou tensão para contribuir com o trabalho na Instituição, pelo contrário, demonstram-se entusiasmados com as atividades que exercem, doando-se afetivamente (MONTEROMARIN et al., 2011; VERARDI et al, 2012; LEITER; MASLACH, 2016). Porém, o fato de que 36,38\% dos pesquisados apresentaram média Exaustão Emocional, necessita que este índice seja controlado de modo que o mesmo diminua através das ações de prevenções da síndrome de Burnout. Maslach e Leiter (2008) afirmam que os indivíduos com pontuação alta em apenas uma das dimensões, podem estar em fase de transição a uma experiência mais completa da Síndrome. Em razão disso, uma única dimensão já serve como um alerta para um problema que está em desenvolvimento no ambiente de trabalho.

A dimensão Despersonalização também apresentou um baixo índice, indicando que a maior parte, $80,36 \%$ dos pesquisados, não demonstram extremas dificuldade de relacionamento com os colegas de trabalho, nem dificuldade de lidar com as tarefas diárias (LEITER; MASLACH, 2016), pois um alto índice leva a comportamentos e sentimentos negativos, fazendo com que o indivíduo passe a culpar o seu próximo pelos seus próprios problemas (GALINDO et al., 2012). Alguns autores como Leiter e Maslach (2015; 2016) e Holm, Torkelson e Bäckström (2016) afirmam que a Despersonalização é a dimensão central e mais distinta da Síndrome de Burnout, pois é nela que a experiência do trabalhador é negativa ou dá errada, devido à falta recursos e a má qualidade das relações sociais, levando o indivíduo ao mau desempenho e 
reduzindo a satisfação em relação ao trabalho. Já a dimensão Envolvimento Pessoal no Trabalho apresentou um resultado positivo, pois esta obteve um alto índice, demonstrando que $83,33 \%$ dos servidores da amostra auto avaliaram-se como pessoas que dão valor e contribuição ao seu trabalho (LEITER; MASLACH, 2016). Ainda, deve-se levar em consideração, que na pesquisa de Schuster (2013), realizada com os servidores da UFSM, encontraram-se índices médios inferiores em todas as dimensões da Síndrome Burnout, em comparação aos índices médios obtidos neste estudo, conforme pode ser observado na Figura 3.

Figura 3 - Percepção da Síndrome de Burnout pelos Servidores da UFSM nos anos de 2013 e 2017

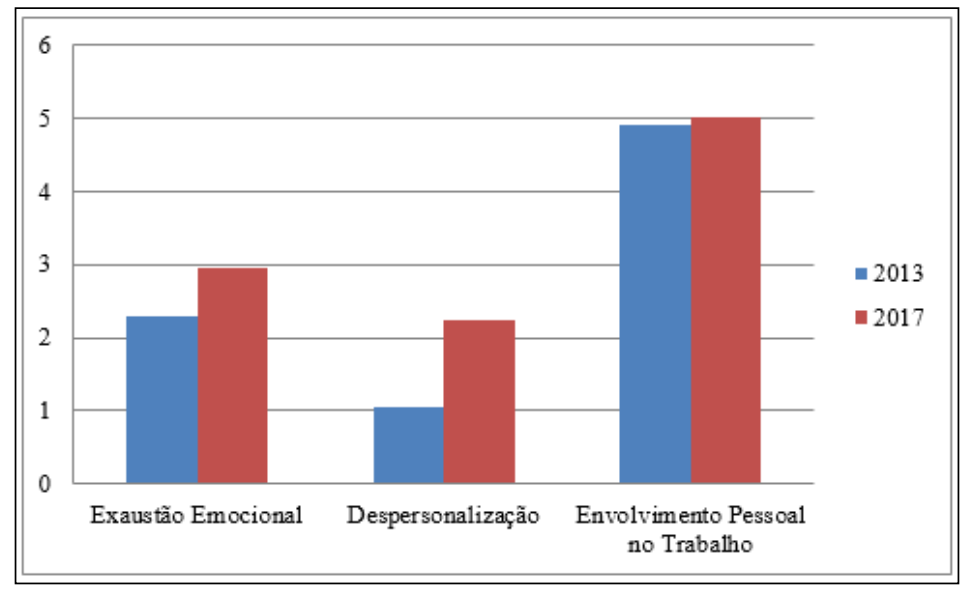

Ao observar a Figura 2, que compara os achados de Schuster (2013) em relação aos deste estudo realizado em 2017, os índices médios que indicam a percepção da Síndrome de Burnout pelos servidores da UFSM aumentaram em todas as dimensões. Obteve-se, respectivamente, o aumento das médias de 2,30 para 2,96 na dimensão Exaustão Emocional, de 1,04 para 2,25 na Despersonalização e de 4,90 para 5,01 no Envolvimento Pessoal no Trabalho. Salienta-se que o crescimento das médias da dimensão Exaustão Emocional e principalmente da Despersonalização, indica que a Instituição deve atentar-se mais aos sintomas provenientes das mesmas, pois de acordo com a pesquisa de Suñer-Soler et al. (2014), a qual associa a Síndrome de Burnout às variáveis ocupacionais, a Exaustão emocional está relacionada ao absenteísmo, deterioração pessoal e familiar, bem como a vontade de desistir da profissão. 
Frente ao exposto, infere-se que este aumento pode ser em decorrência das constantes pressões pela melhora da qualidade do ensino e da prestação de serviços, aliados ao momento atual de escassez dos recursos educacionais e dos cortes governamentais em bolsas, projetos, intercâmbios entre outros, que muitas vezes geram tensões e angustias entre os docentes e técnicos administrativos, afetando diretamente no ambiente organizacional, qualidade de vida no trabalho e consequentemente na saúde física e mental do servidor. Sendo assim, para prevenir que esses índices não continuem crescendo e até mesmo diminuam, encontrou-se suporte teórico em diversos autores, os quais sugerem que para interferir no desenvolvimento da Síndrome de Burnout, algumas ações e mudanças organizacionais devem ser realizadas, como pode ser visto no Quadro 4:

Quadro 4 - Ações organizacionais para prevenir a Síndrome de Burnout

\begin{tabular}{|c|c|}
\hline Ações organizacionais para prevenir a Síndrome de Burnout & Autores \\
\hline $\begin{array}{l}\text { Reorganizar os trabalhos em ambientes seguros e compatíveis com as atividades } \\
\text { desenvolvidas. }\end{array}$ & \multirow{4}{*}{$\begin{array}{l}\text { Sá, Silva e Funchal } \\
\text { (2014) }\end{array}$} \\
\hline Adequar às jornadas de trabalho. & \\
\hline Definir claramente as metas e objetivos da Instituição. & \\
\hline $\begin{array}{l}\text { Fazer com que os indivíduos sejam reconhecidos pela Instituição e cresçam } \\
\text { profissionalmente ao atingirem suas metas. }\end{array}$ & \\
\hline Implementar estratégias a fim de fortalecer o ambiente ético organizacional. & \multirow{2}{*}{$\begin{array}{l}\text { Dalmolin et al. } \\
(2012)\end{array}$} \\
\hline Incentivar o diálogo colaborativo entre os diferentes profissionais. & \\
\hline $\begin{array}{l}\text { Implementar ações ou programas que tenham por objetivo melhorar a } \\
\text { qualidade de vida no trabalho e que mantenham a satisfação entre os } \\
\text { servidores. }\end{array}$ & $\begin{array}{l}\text { Lopes, Ribeiro } \\
\text { e Martinho (2012); } \\
\text { Scchmidt et al. (2013) }\end{array}$ \\
\hline Dispor de ambiente humanizado e com clara comunicação com os superiores. & $\begin{array}{l}\text { Lopes, Ribeiro } \\
\text { e Martinho (2012) }\end{array}$ \\
\hline Incentivar a formação contínua. & \multirow{2}{*}{$\begin{array}{l}\text { Carlotto (2012) } \\
\text { Carvalho e } \\
\text { Magalhães (2013) }\end{array}$} \\
\hline $\begin{array}{l}\text { Realizar o ensino de competências emocionais (autoconhecimento e } \\
\text { autocontrole). }\end{array}$ & \\
\hline
\end{tabular}
Fonte: Elaborado pelos autores.

Com base nas ações e mudanças explanadas anteriormente, acredita-se que a UFSM poderia aderir a algumas ações prestando suporte afetivo e social aos servidores, sendo essa uma maneira de prevenir para que a Síndrome de Burnout não se desenvolva, influenciando também de maneira positiva nas diferentes esferas da vida do indivíduo. 


\subsection{Fatores de risco associados à Síndrome de Burnout}

$\mathrm{Na}$ Tabela 4 podem ser observados os resultados da regressão logística univariada para a amostra dos docentes, considerando como variável dependente a dimensão Exaustão Emocional. Em relação à variável independente "idade", pode-se perceber, a partir dos resultados apresentados na Tabela 4, que ter idade entre 23 e 35 anos diminui em 49,80\% a chance do docente apresentar Exaustão Emocional, comparado com indivíduos maiores de 56 anos. No estudo de Maslach, Schaufeli e Leiter (2001), a variável idade apresentou relação com a Síndrome de Burnout. Neste sentido, alguns estudos indicam que os indivíduos com idade inferior a 30 anos possuem níveis de Exaustão Emocional mais elevados (SOWMYA; PANCHANATHAM, 2011), indo de encontro aos achados deste estudo. Com relação ao tempo de serviço, pode-se verificar que os docentes que apresentaram tempo de serviço de 0 a 10 anos possuem $42 \%$ menos chance de ter exaustão emocional, quando comparados com docentes que apresentam 21 ou mais anos de serviço.

Tabela 4 - Regressão logística univariada para a amostra dos docentes, considerando como variável dependente a dimensão Exaustão Emocional

\begin{tabular}{|c|c|c|c|c|}
\hline Variáveis & & OR bruto & IC 95\% & p-valor \\
\hline \multicolumn{5}{|c|}{ Variável dependente: Exaustão emocional } \\
\hline \multirow{2}{*}{ Sexo } & Feminino- 0 & 1 & & \multirow{2}{*}{0,621} \\
\hline & Masculino- 1 & 0,914 & 0,639-1,307 & \\
\hline \multirow{3}{*}{ Idade } & $\geq 56$ anos -0 & 1 & & 0,068 \\
\hline & 36 a 55 anos -1 & 0,675 & $0,423-1,077$ & 0,099 \\
\hline & 23 a 35 anos- 2 & 0,502 & $0,279-0,903$ & 0,022 \\
\hline \multirow{3}{*}{ Escolaridade } & Doutorado- 0 & 1 & & 0,503 \\
\hline & Mestrado- 1 & 0,839 & $0,497-1,418$ & 0,512 \\
\hline & Graduação ou especialização- 2 & 0,59 & $0,214-1,630$ & 0,309 \\
\hline \multirow{3}{*}{ Tempo de serviço } & $\geq 21$ anos- 0 & 1 & & 0,004 \\
\hline & 11 a 20 anos -1 & 1,145 & $0,652-2,014$ & 0,637 \\
\hline & 0 a 10 anos- 2 & 0,58 & $0,367-0,916$ & 0,02 \\
\hline \multirow{2}{*}{ Categoria do cargo } & Professor ensino superior- 0 & 1 & \multirow{2}{*}{$0,286-1,230$} & \multirow{2}{*}{0,161} \\
\hline & Professor técnico- 1 & 0,593 & & \\
\hline \multirow{2}{*}{ Férias } & Não- 0 & 1 & \multirow{2}{*}{$0,518-1,624$} & \multirow{2}{*}{0,766} \\
\hline & Sim- 1 & 0,917 & & \\
\hline \multirow[t]{2}{*}{ Chefia } & Sim- 0 & 1 & \multirow{2}{*}{$0,820-1,913$} & \multirow{2}{*}{0,297} \\
\hline & Não- 1 & 1,253 & & \\
\hline \multirow{2}{*}{ Carga horária } & 20 ou 40 horas- 1 & 1 & \multirow{2}{*}{$0,555-1,235$} & \\
\hline & mais que 40 horas- 0 & 0,828 & & 0,355 \\
\hline \multirow{2}{*}{$\begin{array}{l}\text { Exerce o trabalho que } \\
\text { gosta }\end{array}$} & Não- 0 & 1 & \multirow{2}{*}{$0,593-7,489$} & \multirow{2}{*}{0,249} \\
\hline & Sim- 1 & 2,107 & & \\
\hline
\end{tabular}


Pode-se observar que as variáveis candidatas a entrarem em um modelo de regressão múltiplo, capazes de explicar a exaustão emocional, são as seguintes: a idade, o tempo de serviço, a categoria do cargo e exerce o trabalho que gosta, pois estas apresentaram $p$-valor $\leq 0,25$. Na Tabela 5 pode ser observada a regressão logística univariada considerando como variável dependente a dimensão Despersonalização. Analisando a significância das variáveis independentes individualmente, pode-se observar que nenhuma apresentou p-valor $\leq 0,05$, ou seja, estas não foram significativas nos modelos de regressão univariados.

Tabela 5 - Regressão logística univariada para a amostra dos docentes, considerando como variável dependente a dimensão Despersonalização.

\begin{tabular}{|c|c|c|c|c|}
\hline Variáveis & & OR bruto & IC 95\% & p-valor \\
\hline \multicolumn{5}{|c|}{ Variável dependente: Despersonalização } \\
\hline \multirow{2}{*}{ Sexo } & Feminino-0 & 1 & & \multirow{2}{*}{0,474} \\
\hline & Masculino-1 & 1,234 & $0,694-2,197$ & \\
\hline \multirow{3}{*}{ Idade } & $>56$ anos -0 & 1 & & 0,888 \\
\hline & 36 a 55 anos -1 & 0,834 & $0,393-1,769$ & 0,636 \\
\hline & 23 a 35 anos- 2 & 0,833 & $0,331-2,096$ & 0,699 \\
\hline \multirow{3}{*}{ Escolaridade } & Doutorado-0 & 1 & & 0,746 \\
\hline & Mestrado-1 & 0,942 & $0,408-2,178$ & 0,889 \\
\hline & Graduação ou especialização (2) & 0,455 & $0,060-3,467$ & 0,447 \\
\hline \multirow{3}{*}{$\begin{array}{l}\text { Tempo de } \\
\text { serviço }\end{array}$} & $>21$ anos-0 & 1 & & 0,122 \\
\hline & 11 a 20 anos -1 & 0,832 & $0,358-1,934$ & 0,669 \\
\hline & 0 a 10 anos- 2 & 0,51 & $0,256-1,016$ & 0,056 \\
\hline Categoria do & Professor ensino superior- 0 & 1 & & \multirow{2}{*}{0,132} \\
\hline cargo & Professor técnico-1 & 0,214 & $0,029-1,587$ & \\
\hline \multirow{2}{*}{ Férias } & Não-0 & 1 & & \multirow{2}{*}{0,548} \\
\hline & Sim-1 & 1,296 & $0,556-3,018$ & \\
\hline \multirow[t]{2}{*}{ Chefia } & Sim-0 & 1 & & \multirow{2}{*}{0,128} \\
\hline & Não-1 & 1,835 & $0,840-4,006$ & \\
\hline \multirow{2}{*}{ Carga horária } & 20 ou 40 horas- 1 & 1 & & \multirow{2}{*}{0,359} \\
\hline & mais que 40 horas- 0 & 0,747 & $0,400-1,394$ & \\
\hline \multirow{2}{*}{ Exerce o trabalho que gosta } & Não-0 & 1 & & \multirow{2}{*}{0,68} \\
\hline & Sim-1 & 1,537 & $0,199-11,88$ & \\
\hline
\end{tabular}

Pode-se observar que as variáveis candidatas a entrarem no modelo múltiplo, capazes de explicar a dimensão Despersonalização, consistem em: tempo de serviço, categoria do cargo e a chefia, pois estas apresentaram p-valor $\leq 0,25$.

Na Tabela 6 pode ser observada a regressão logística univariada considerando como variável dependente a dimensão Envolvimento pessoal no trabalho. 
Tabela 6 - Regressão logística univariada para a amostra dos docentes, considerando como variável dependente a dimensão Envolvimento pessoal no trabalho.

\begin{tabular}{|c|c|c|c|c|}
\hline Variáveis & & OR bruto & IC $95 \%$ & $p$-valor \\
\hline \multicolumn{5}{|c|}{ Variável dependente: Envolvimento pessoal no trabalho } \\
\hline \multirow{3}{*}{ Sexo } & Feminino-0 & 1 & & \\
\hline & Masculino-1 & 0,852 & $0,398-1,823$ & 0,68 \\
\hline & $>56$ anos -0 & 1 & & 0,389 \\
\hline \multirow[t]{3}{*}{ Idade } & 36 a 55 anos -1 & 0,506 & $0,148-1,735$ & 0,279 \\
\hline & 23 a 35 anos -2 & 0,88 & $0,192-4,036$ & 0,87 \\
\hline & Doutorado-0 & 1 & & 0,304 \\
\hline \multirow[t]{3}{*}{ Escolaridade } & Mestrado-1 & 4,869 & $0,652-36,361$ & 0,123 \\
\hline & Graduação ou especialização (2) & & & \\
\hline & $>21$ anos-0 & 1 & & 0,669 \\
\hline \multirow[t]{2}{*}{ Tempo de serviço } & 11 a 20 anos -1 & 1,66 & $0,470-5,858$ & 0,431 \\
\hline & 0 a 10 anos-2 & 1,431 & $0,577-3,549$ & 0,44 \\
\hline \multirow{2}{*}{ Categoria do cargo } & Professor ensino superior-0 & 1 & & 4902 \\
\hline & Professor técnico-1 & 1,42 & $0,411-4,902$ & 4,902 \\
\hline \multirow{2}{*}{ Férias } & Não-0 & 1 & & \multirow{2}{*}{0,49} \\
\hline & Sim-1 & 1,674 & $0,388-7,230$ & \\
\hline \multirow[t]{2}{*}{ Chefia } & Sim-0 & 1 & & \multirow{2}{*}{0,204} \\
\hline & Não-1 & 0,497 & $0,169-1,460$ & \\
\hline \multirow{2}{*}{ Carga horária } & 20 ou 40 horas- 1 & 1 & & \multirow{2}{*}{0,902} \\
\hline & mais que 40 horas- 0 & 0,946 & $0,394-2,276$ & \\
\hline \multirow{2}{*}{ Exerce o trabalho que gosta } & Não-0 & 1 & & \multirow{2}{*}{0,825} \\
\hline & Sim-1 & 1,262 & $0,161-9,908$ & \\
\hline
\end{tabular}

Analisando a significância das variáveis independentes pode-se perceber que nenhuma apresentou p-valor $\leq 0,05$, ou seja, estas não foram significativas nos modelos de regressão univariados. Pode-se observar que apenas uma variável atende ao critério do $p$-valor $\leq 0,25$ e seria candidata a entrar no modelo de regressão logística múltiplo, sendo esta a variável "chefia". Após a realização da regressão logística univariada, considerando as três dimensões da Síndrome de Burnout como variáveis dependentes, foram testadas, nos modelos de regressão múltipla, as variáveis independentes que apresentaram $p$-valor $\leq 0,25$. Após a inserção de todas as variáveis nos modelos múltiplos, foram excluídas, de maneira decrescente, as variáveis que apresentaram pvalor $>0,05$. Pode-se verificar, que para a amostra de docentes deste estudo, não foi possível encontrar um modelo de regressão múltiplo que explicasse o nível de Exaustão Emocional, Despersonalização e Envolvimento Pessoal no Trabalho, a partir das variáveis do perfil coletadas. 
Na Tabela 7 pode ser observada a regressão logística univariada para a amostra dos técnicos administrativos, considerando como variável dependente a dimensão Exaustão Emocional. Em relação à variável independente "idade", verificou-se que ter idade entre 23 e 35 anos diminui em 43,00\% a chance de apresentar Exaustão Emocional, comparado com indivíduos maiores de 56 anos. Com relação ao tempo de serviço, pode-se verificar que os técnicos administrativos que apresentam tempo de serviço de 0 a 10 anos possuem 36\% menos chance de ter Exaustão Emocional, quando comparados com os técnicos administrativos que apresentam 21 ou mais anos de serviço.

Tabela 7 - Regressão logística univariada para a amostra dos técnicos administrativos, considerando como variável dependente a dimensão Exaustão emocional.

\begin{tabular}{|c|c|c|c|c|}
\hline \multicolumn{2}{|c|}{ Variáveis } & \multirow[t]{2}{*}{ OR bruto } & \multirow[t]{2}{*}{ IC 95\% } & \multirow[t]{2}{*}{ p-valor } \\
\hline Variável dependent & e: Exaustão emocional & & & \\
\hline \multirow{2}{*}{ Sexo } & Feminino - 0 & 1 & & \multirow{2}{*}{0,741} \\
\hline & Masculino - 1 & 1,046 & $0,798-1,372$ & \\
\hline \multirow{3}{*}{ Idade } & $>56$ anos -0 & 1 & & 0,016 \\
\hline & 36 a 55 anos -1 & 0,821 & $0,552-1,219$ & 0,329 \\
\hline & 23 a 35 anos -2 & 0,57 & $0,370-0,876$ & 0,01 \\
\hline \multirow{5}{*}{ Escolaridade } & Doutorado - 0 & 1 & & 0,651 \\
\hline & Mestrado - 1 & 1,005 & $0,470-2,150$ & 0,989 \\
\hline & Especialização - 2 & 0,805 & $0,382-1,692$ & 0,567 \\
\hline & Graduação - 3 & 0,841 & $0,392-1,801$ & 0,656 \\
\hline & Primeiro e segundo grau - 4 & 1,045 & $0,464-2,349$ & 0,916 \\
\hline \multirow{3}{*}{ Tempo de serviço } & $>21$ anos -0 & 1 & & 0,016 \\
\hline & 11 a 20 anos -1 & 0,741 & $0,4892-1,123$ & 0,158 \\
\hline & 0 a 10 anos -2 & 0,639 & $0,470-0,868$ & 0,004 \\
\hline \multirow{5}{*}{ Categoria do cargo } & Classe A & 1,799 & $0,676-2,456$ & 0,255 \\
\hline & Classe B & 1,966 & $0,755-5,118$ & 0,166 \\
\hline & Classe C & 1,457 & $0,963-2,205$ & 0,075 \\
\hline & Classe D & 1.392 & $1,032-1,877$ & 0,082 \\
\hline & Classe E & 1 & & \\
\hline \multirow{2}{*}{ Férias } & Não - 0 & 1 & \multirow{2}{*}{$0,700-1,318$} & \multirow{2}{*}{0,805} \\
\hline & Sim - 1 & 0,961 & & \\
\hline \multirow[t]{2}{*}{ Chefia } & Sim - 0 & 1 & \multirow{2}{*}{$0,732-1,426$} & \multirow{2}{*}{0,889} \\
\hline & Não - 1 & 1,022 & & \\
\hline \multirow{3}{*}{ Carga horária } & 40 e acima de 40 horas- 0 & 1 & & 0,604 \\
\hline & 30 horas- 1 & 1,021 & $0,760-1,370$ & 0,89 \\
\hline & 20 horas- 2 & 1,538 & $0,663-3,565$ & 0,315 \\
\hline \multirow{2}{*}{$\begin{array}{l}\text { Exerce o trabalho } \\
\text { que gosta }\end{array}$} & Não-0 & 1 & & \multirow{2}{*}{0,873} \\
\hline & Sim-1 & 1,038 & $0,659-1,631$ & \\
\hline
\end{tabular}


Pode-se observar que as variáveis candidatas a entrarem em um modelo múltiplo, capazes de explicar a Exaustão Emocional, são a idade e o tempo de serviço, pois estas apresentaram $p$-valor $\leq 0,25$.

Na Tabela 8 pode ser observada a regressão logística univariada, considerando como variável dependente a dimensão Despersonalização. Analisando a significância das variáveis independentes, pode-se perceber que nenhuma apresentou p-valor $\leq 0,05$, ou seja, estas não foram significativas nos modelos de regressão univariados.

Tabela 8 - Regressão logística univariada para a amostra dos Técnicos administrativos, considerando como variável dependente a dimensão Despersonalização.

\begin{tabular}{|c|c|c|c|c|}
\hline \multicolumn{2}{|l|}{ Variáveis } & OR bruto & IC 95\% & p-valor \\
\hline \multicolumn{5}{|c|}{ Variável dependente: Despersonalização } \\
\hline \multirow{2}{*}{ Sexo } & Feminino - 0 & 1 & & \multirow{2}{*}{0,278} \\
\hline & Masculino - 1 & 1,238 & $0,842-1,822$ & \\
\hline \multirow{3}{*}{ Idade } & $>56$ anos -0 & 1 & & 0,438 \\
\hline & 36 a 55 anos -1 & 1,365 & $0,712-2,615$ & 0,348 \\
\hline & 23 a 35 anos -2 & 1,553 & $0,790-3,052$ & 0,202 \\
\hline \multirow{5}{*}{ Escolaridade } & Doutorado-0 & 1 & & 0,295 \\
\hline & Mestrado-1 & 0,58 & $0,232-1,455$ & 0,246 \\
\hline & Especialização-2 & 0,419 & $0,170-1,032$ & 0,058 \\
\hline & Graduação-3 & 0,606 & $0,243-1,513$ & 0,284 \\
\hline & Primeiro e segundo grau-4 & 0,469 & $0,168-1,312$ & 0,149 \\
\hline \multirow{3}{*}{ Tempo de serviço } & $>21$ anos-0 & 1 & & 0,185 \\
\hline & 11 a 20 anos -1 & 0,84 & $0,429-1,643$ & 0,61 \\
\hline & 0 a 10 anos- 2 & 1,352 & $0,857-2,134$ & 0,195 \\
\hline \multirow{5}{*}{ Categoria do cargo } & Classe A & 1,111 & $0,980-2,567$ & 0,789 \\
\hline & Classe B & 1,021 & $0,990-1,233$ & 0,897 \\
\hline & Classe C & 1.567 & $0,567-1,953$ & 0,89 \\
\hline & Classe D & 1,345 & $1,256-2,564$ & 0,765 \\
\hline & Classe E & 1 & & \multirow{3}{*}{0,652} \\
\hline \multirow{2}{*}{ Férias } & Não-0 & 1 & & \\
\hline & Sim-1 & 1,108 & $0,710-1727$ & \\
\hline \multirow[t]{2}{*}{ Chefia } & Sim-0 & 1 & & \multirow{2}{*}{0,216} \\
\hline & Não-1 & 1,387 & $0,826-2,330$ & \\
\hline \multirow{3}{*}{ Carga horária } & 40 e acima de 40 horas- 0 & 1 & & 0,128 \\
\hline & 30 horas- 1 & 0,886 & $0,573-1,370$ & 0,587 \\
\hline & 20 horas- 2 & 2,493 & $0,954-6,508$ & 0,062 \\
\hline \multirow{2}{*}{$\begin{array}{l}\text { Exerce o trabalho } \\
\text { que gosta }\end{array}$} & Não-0 & 1 & & \multirow{2}{*}{0,432} \\
\hline & Sim-1 & 0,785 & $0,429-1,436$ & \\
\hline
\end{tabular}


Pode-se observar que as variáveis candidatas a entrarem em um modelo múltiplo, capazes de explicar a Despersonalização, são o tempo de serviço, a chefia e a carga horária, pois estas apresentaram $p$-valor $\leq 0,25$. Na Tabela 9 pode ser observada a regressão logística univariada, considerando como variável dependente a dimensão Envolvimento pessoal no trabalho.

Tabela 9 - Regressão logística univariada para a amostra dos técnicos administrativos, considerando como variável dependente a dimensão Envolvimento pessoal no trabalho.

\begin{tabular}{|c|c|c|c|c|}
\hline Variáveis & & OR bruto & IC 95\% & p-valor \\
\hline \multicolumn{5}{|c|}{ Variável dependente: Envolvimento pessoal no trabalho } \\
\hline \multirow{2}{*}{ Sexo } & Feminino-0 & 1 & & \multirow{2}{*}{0,756} \\
\hline & Masculino-1 & 0,912 & $0,509-1,633$ & \\
\hline \multirow{3}{*}{ Idade } & $>56$ anos -0 & 1 & & 0,501 \\
\hline & 36 a 55 anos -1 & 0,958 & $0,410-2,238$ & 0,920 \\
\hline & 23 a 35 anos- 2 & 1,439 & $0,553-3,742$ & 0,455 \\
\hline \multirow{5}{*}{ Escolaridade } & Doutorado-0 & 1 & & 0,425 \\
\hline & Mestrado-1 & 0,740 & $0,091-6,034$ & 0,778 \\
\hline & Especialização-2 & 0,539 & $0,070-4,149$ & 0,553 \\
\hline & Graduação-3 & 0,760 & $0,093-6,204$ & 0,798 \\
\hline & Primeiro e segundo grau-4 & 0,340 & $0,041-2,790$ & 0,315 \\
\hline \multirow{3}{*}{ Tempo de serviço } & $>21$ anos-0 & 1 & & 0,717 \\
\hline & 11 a 20 anos -1 & 1,310 & $0,527-3,259$ & 0,561 \\
\hline & 0 a 10 anos-2 & 1,288 & $0,675-2,455$ & 0,443 \\
\hline \multirow{5}{*}{ Categoria do cargo } & Classe A & 0,890 & $0,768-2,334$ & 0,890 \\
\hline & Classe B & 0,777 & $0,678-2,343$ & 0,567 \\
\hline & Classe C & 1,235 & $0,908-1,789$ & 0,321 \\
\hline & Classe D & 1,538 & $0,765-1,453$ & 0,099 \\
\hline & Classe E & 1 & & \\
\hline \multirow{2}{*}{ Férias } & Não-0 & 1 & & \multirow{2}{*}{0,624} \\
\hline & Sim-1 & 1,195 & $0,586-2,438$ & \\
\hline \multirow[t]{2}{*}{ Chefia } & Sim-0 & 1 & & \multirow{2}{*}{0,509} \\
\hline & Não-1 & 0,770 & $0,354-1,673$ & \\
\hline \multirow{3}{*}{ Carga horária } & 40 e acima de 40 horas- 0 & 1 & & 0,675 \\
\hline & 30 horas- 1 & 1,137 & $0,589-2,193$ & 0,703 \\
\hline & 20 horas- 2 & 0,566 & $0,127-2,517$ & 0,455 \\
\hline \multirow{2}{*}{$\begin{array}{l}\text { Exerce o trabalho } \\
\text { que gosta }\end{array}$} & Não-0 & 1 & & \multirow{2}{*}{0,527} \\
\hline & Sim-1 & 1,330 & $0,550-3,216$ & \\
\hline
\end{tabular}


Após a realização da regressão logística univariada considerando as três dimensões da Síndrome de Burnout como variáveis dependentes, foram testadas, nos modelos de regressão múltipla, as variáveis independentes que apresentaram p-valor $\leq 0,25$. Após a inserção de todas as variáveis no modelo, foram excluídas, de maneira decrescente, as variáveis que apresentaram p-valor $>0,05$.

Pode-se verificar, que para a amostra de técnicos administrativos deste estudo, não foi possível encontrar um modelo de regressão múltiplo que explicasse o nível de Exaustão Emocional, Despersonalização e Envolvimento Pessoal no Trabalho, a partir das variáveis sociodemográficas e socioprofissionais coletadas.

\section{CONCLUSÃO}

Ao longo das últimas duas décadas, tem havido um interesse crescente nas experiências afetivas, estressoras e emocionais no trabalho. Os estudos nessa área são diversos com pesquisas que avaliam o papel do humor, das emoções e da motivação dos funcionários (EREZ; ISEN, 2002), o desempenho no trabalho (LAW; WONG; SONG, 2004) e a criatividade.

Devido às mundanças no mundo do trabalho, a Síndrome de Burnout vem sendo estudada em diversos ambientes organizacionais, com profissionais de diferentes áreas. Diante disso, este estudo teve como objetivo analisar os fatores de risco associados ao desenvolvimento da Síndrome de Burnout em servidores da UFSM.

Pode-se verificar, a partir da pesquisa realizada, que a grande maioria dos docentes e técnicos administrativos participantes da amostra do estudo não apresentaram nível considerado da Síndrome de Burnout, pois a maior parte destes demonstraram baixa Exaustão Emocional e Despersonalização, considerados estes os fatores que contribuem para o surgimento da Síndrome e, elevado Envolvimento Pessoal no Trabalho, fator este que demonstra que os respondentes estão comprometidos com as suas atividades diárias e que estes percebem que estão contribuindo de maneira positiva para a realização do seu trabalho.

Apesar da maioria dos servidores demonstrarem baixa Exaustão Emocional e Despersonalização, não se pode deixar de destacar aqueles servidores que apresentaram estar exaustos emocionalmente e com sentimentos de 
despersonalização, o que indica que a insituição deve se manter atenta aos sintomas de desenvolvimento da Síndrome, pois segundo o estudo de Suñer-Soler et al. (2014), no qual é analisado a associação da Síndrome de Burnout às variáveis ocupacionais, fatores como o absenteísmo, deterioração pessoal e familiar e a vontade de desistir da profissão estão relacionados com o sentimento de Exaustão Emocional. Além disso, Carlotto (2012) destaca que sentimentos como a Despersonalização podem causar o distanciamento nas relações profissionais, principalmente no que se refere ao professor e aluno, o que pode ser prejudicial ao processo de ensino e aprendizagem.

Em relação aos fatores de risco para o desenvolvimento da Síndrome de Burnout, foi possivel verificar, no modelo de regressão logística univariado, que ter idade entre 23 e 35 anos diminui em 49,80\% a chance do docente e $43,00 \%$ do técnico administrativo apresentarem exaustão emocional, comparado com indivíduos maiores de 56 anos e que, em relação ao tempo de serviço, os docentes e TAEs que apresentaram tempo de 0 a 10 anos de instituição, possuem 42\% e 36\%, respectivamente, menos chance de ter exaustão emocional quando comparados com docentes e TAEs que apresentam 21 ou mais anos de serviço. Tais fatos demonstraram que os docentes e TAEs que estão trabalhando há menos tempo na instituição possuem menos Exaustão Emocional, ou seja, demonstram, em menor nível, sensações como a falta energia, fadiga, sobrecarga e esgotamento moral, físico, emocional e psicológico.

Por fim, não foi possível encontrar um modelo de regressão logística múltiplo para os docentes e técnicos administrativos, o que pode ser devido ao fato de que variáveis como: tempo frente ao aluno em sala de aula, quantidades de disciplinas ministradas, ambiente físico, número de filhos, normas institucionais, clima, burocracia, autonomia, segurança, recompensas, sobrecarga, relação profissionalcolegas, conflito de papel, desvio de função, ambiguidade de papel, suporte organizacional, satisfação, pressão, possibilidade de progresso, conflito com valores pessoais, suporte social, suporte familiar, cultura, prestígio e percepção de inequidade, citadas por Benevides-Pereira (2010) como fatores que podem contribuir para o desenvolvimento da Síndrome de Burnout, não foram medidas. 
Como limitação do estudo, destaca-se o fato de que não foi realizada uma amostragem probabilística, portanto estes resultados não podem ser inferidos para a população de TAEs e docentes da UFSM.

Como sugestões para estudos futuros, recomenda-se realizar um estudo no qual seja ampliada a coleta das características pessoais dos respondentes, podendo-se expandir a discussão sobre os fatores de risco associados ao desenvolvimento da Síndrome de Burnout. 


\section{REFERÊNCIAS}

ALMEIDA KM, SOUZA LA, CARLOTTO MS. Síndrome de Burnout em Funcionários de uma Fundação de Proteção e Assistência Social. Rev. psicol. organ. trab. 2009;9(2):86-96.

BAKKER AB. The crossover of burnout and work engagement among working couples. Hum. relat. 2005;58(5):661-689.

BAKKER AB, DEMEROUTI E, SCHAUFELI WB. Validation of the Maslach Burnout Inventory - General Survey: An Internet study. Anxiety Stress Copin. 2002;15(3):245-260.

BAUK DA. Stress. Rev. bras. saúde ocup. 1985;13(50):28-36.

BENEVIDES-PEREIRA AMT. O processo de adoecer pelo trabalho. In: Benevides-Pereira, A.M.T. (org.). Burnout: quando o trabalho ameaça o bem-estar do trabalhador. 4 ed. São Paulo: Casa do Psicólogo; 2002.

BENEVIDES-PEREIRA AMT. Burnout: Quando o trabalho ameaça o bem-estar do trabalhador. 4 ed. São Paulo: Casa do Psicólogo; 2010.

BRASIL; Conselho Nacional de Saúde. Resolução n. 196, de 10 de outubro de 1996. Aprova as diretrizes e normas regulamentadoras de pesquisas envolvendo seres humanos. Diário Oficial da República Federativa do Brasil, Brasília (DF). 1996. Available from: http://conselho.saude.gov.br/resolucoes/1996/reso196.doc.

BRASIL; Lei n. 9.610, de 19 de fevereiro de 1998. Altera, atualiza e consolida a legislação sobre direitos autorais e dá outras providências. Diário Oficial da República Federativa do Brasil, Brasília (DF). 1988. Available from: http://www.planalto.gov.br/ccivil_03/leis//9610.htm.

CARLOTTO MS, CÂMARA SG. Análise da produção científica sobre a síndrome de burnout no Brasil. Psico. 2008;39(2):152-158.

CARLOTTO MS, PALAZZO, L. Síndrome de burnout e fatores associados: um estudo epidemiológico com professores. Cad. saúde pública. 2006;22(5):1017-1026.

CARLOTTO MS. Síndrome de burnout em professores: avaliação, fatores associados e intervenção. Porto, Portugal: LivPsic; 2012.

CARVALHO CG, MAGALHÃES SR. Quem cuida do cuidador: principais fatores que interferem na saúde dos profissionais de enfermagem, uma visão biopsicossocial. Journal of Research: Fundamental Care On Line. 2013;5(3):122-131.

CASINI A, HUBERT C, KAELEN R. Professional recognition as protective factor against burnout. Eur. Health Psychol. 2016;18. 
CHAN DW. Emotional intelligence and components of burnout among Chinese secondary school teachers in Hong Kong. Teaching and teacher education. 2006;22(8):1042-1054.

DALMOLIN GL, LUNARDI VL, BARLEM ELD, SILVEIRA, R. S. Implicações do sofrimento moral para os (as) enfermeiros(as) e aproximações com Burnout. Texto \& contexto enferm. 2012;21(1):200-208.

EREZ A, ISEN AM. The influence of positive affect on the components of expectancy motivation. J. Appl. Soc. Psychol. 2002;87(6):1055-1067.

FARBER BA. Crisis in education. Stress and burnout in the american teacher. São Francisco: Jossey-Bass Inc; 1991.

FONSECA RTM. Saúde Mental para e pelo Trabalho. Saúde mental no trabalho: coletânea do fórum de saúde e segurança no trabalho do Estado de Goiás/coordenação geral. Goiânia: Cir Gráfica; 2013 [cited 2018 out 2018]. Available from: http://bibliotecaprt21.files.wordpress.com/2013/09/livro-saude-mental-notrabalho-2013-prt18.pdf.

FRANÇA HHA. Síndrome de Burnout. Revista Brasileira de Medicina. 1987;44(8):197199.

FREITAS AKB, BRITO LC, OBREGON SL, LOPES LFD. Estresse, Coping e Síndrome de Burnout em policiais rodoviários federais. Saber humano. 2015;5(7):106-125.

GALINDO RH, FELICIANO KVO, LIMA RAS, SOUZA Al. Síndrome de Burnout entre enfermeiros de um hospital geral da cidade do Recife. Rev. Esc. Enferm. 2012;46(2):420-427.

GARCIA GFB. Meio ambiente do trabalho: direito, segurança e medicina do trabalho. 4.ed. Rio de Janeiro: Forense; 2014.

GORSKI GM. Relação entre atividade física no lazer e burnout em trabalhadores da indústria [dissertation]. Ponta Grossa: Universidade Tecnológica Federal do Paraná; 2015. 95 p.

HAIR JF, BLACK, ANDERSON RE, TATHAM RL. Análise multivariada de dados. 6. ed. Porto Alegre: Bookman; 2009.

HOLM E, TORKELSON M, BÄCKSTRÖM. New Types of employment, new ways to be uncivil? A thematic analysis of temporary agency workersä exposure to workplace incivility. Psychology. 2016;7(01):74-84. 
INNSTRAND ST, LANGBALLE EM, FALKUM E, AASLAND OG. Exploring within- and between-gender differences in burnout: different occupational groups. Int Arch Occ Env Hea. 2011;84(7):813-824.

LAW KS, WONG CS, SONG L. Construct and Criterion Validity of Emotional Intelligence and ItsPotential Utility for Management Studies. Int. J. Appl. Psychol. 2004;89(3):48396.

LEITER MP, MASLACH C. Conquering burnout. Scientific American Mind. 2015;26:3035.

LEITER MP, MASLACH C. Latent burnout profiles: A new approach to understanding the burnout experience. Burnout Research. 2016;3:89-100, 2016.

LIMONGI-FRANÇA AC, RODRIGUES AL. Estresse e Trabalho: Uma abordagem psicossomática. São Paulo: Atlas; 2012.

LIPP M. Pesquisas sobre stress no Brasil: saúde, ocupações e grupos de risco. Campinhas; 1996.

LOPES LFD. Métodos Quantitativos. 1 ed. Santa Maria: UFSM; 2016.

LOPES CCP, RIBEIRO TP, MARTINHO NJ. Síndrome de Burnout e sua relação com a ausência de qualidade de vida no trabalho do enfermeiro. Enferm. Foco. 2012;3(2):97101.

MASLACH C. "Burned-out". Human Behavior. 1976;5(9):22-26.

MASLACH C. Entendendo o Burnout. In: ROSSI, A. M.; PERREWÉ, P. L.; SAUTER, S. L. Stress e qualidade de vida no trabalho: perspectivas atuais da saúde ocupacional. São Paulo: Atlas; 2007.

MASLACH C, JACKSON S. E. The measurement of experienced burnout. J. Organ. Behav. 1981;2:99-113.

MASLACH C, LEITER MP. Early predictors of job burnout and engagement. Int. J. Appl. Psychol. 2008;93(3):498-512.

MASLACH C, LEITER MP. Trabalho: Fonte de Prazer ou desgaste? Guia para vencer o estresse na empresa (M. S. Martins, Trad). Campinas: papiros; 1999.

MASLACH C, SCHAUFELI WB, LEITER MP. Job burnout. Annu Rev Psychol. 2001;52:397422. 
MONTERO-MARIN J, MONTICELLI F, CASA M, ROMAN A, TOMAS I, GILI M, GARCIACAMPAYO J. Burnout syndrome among dental students: a short version of the "Burnout Clinical Subtype Questionnaire" adapted for students (BCSQ-12-SS). BMC Medical Education. 2011;11(103):1-11.

NAIR AG, JAIN P, AGARWAL A, JAIN V. Work satisfaction, burnout and gender-based inequalities among ophthalmologists in India: A survey. Work (Reading, Mass.). 2017;56(2):221-228.

PERRERÉ PL, ROSSI A, SAUTER S. Stress e qualidade de vida no trabalho: perspectivas atuais da saúde ocupacional. São Paulo: Atlas; 2007.

PINTO AM. Burnout profissional em professores portugueses: representações sociais, incidência e preditores [thesis]. Lisboa: Universidade de Lisboa; 2000. 504 p.

RAWOLLE M, WALLIS MS, BADHAM R, KEHR HM. No fit, no fun: The effect of motive incongruence on job burnout and the mediating role intrinsic motivation. Pers. Individ. Differ. 2016;89:65-68.

REIS EJFB, ARAUJO TM, CARVALHO FM, BARBALHO L, SILVA MO. Docência e exaustão emocional. Educ. Soc.2006;27(94):229-253.

SÁ MAS, SILVA POM, FUNCHAL B. Burnout: o impacto da satisfação no trabalho em profissionais de enfermagem. Psicol. Soc. 2014;26(3):664-674.

SCCHMIDT DRC, PALADINE M, BIATO C, PAIS JD, OLIVEIRA AR. Qualidade de vida no trabalho e Burnout em trabalhadores de enfermagem da Unidade de Terapia Intensiva.

Rev. bras. Enferm. 2013;66(1):13-7.

SCHAUFELI WB, BUUNK BP. Burnout: an overview of 25 years of research and theorizing. In M. J. Schabracq, J. A. M. Winnubst, \& C. L. Cooper (Eds.), Handbook of work and health psychology (pp. 383-425). Chichester: Wiley; 2003.

SCHAUFELI WB, SALANOVA M, GONZÁLEZ-ROMÁ V, BAKKER AB. The measurement of engagement and burnout: a two sample confirmatory factor analytic approach. J. Happiness Stud. 2002;3:71-92.

SCHUSTER, MS. Explorando a justiça organizacional, burnout e saúde nos servidores da UFSM [dissertation]. Santa Maria: Universidade Federal de Santa Maria; 2013. $117 \mathrm{p}$.

SELYE, H. Stress: a tensão da vida. São Paulo: IBRASA; 1959. 
SOWMYA KR, PANCHANATHAN N. Factors insuencing organizational commitment of banking sector employees. Journal of Economics and Behavioral Studies. 2011;2(1):19-25.

SUÑER-SOLER R, GRAU-MARTÍNA A, FLICHTENTREID D, PRATSD M, BRAGAD F, FONTMAYOLASA $S$, et al. The consequences of burnout syndrome among healthcare professionals in Spain and Spanish speaking Latin American countries. Burn. Res. 2014;(1):82-89.

TAMAYO MR. Burnout: Relação com a afetividade negativa, o coping no trabalho e a percepção de suporte organizacional [thesis]. Brasília: Universidade de Brasília; 2002.

TAMAYO MR. Burnout: Aspectos gerais e relação com o estresse no trabalho. In A. Tamayo (Ed.), Estresse e cultura organizacional. São Paulo: Casa do Psicólogo; 2008.

VERARDI CEL, MIYAZAKI MCOS, NAGAMINE KK, LOBO APS, DOMINGOS NAM. Esporte, stress e burnout. Estud. Psicol. 2012;29(3):305-313.

ZANELLI JC. Estresse nas organizações de trabalho. Compreensão e Intervenção baseada em evidências. Porto Alegre: Artmed; 2010.

ZANINI RR. Modelos multiníveis aplicados ao estudo da mortalidade infantil no Rio Grande do Sul, Brasil, de 1994 a 2004 [thesis]. Porto Alegre: Universidade Federal do Rio Grande do Sul; 2007. 200 p. 